AperTO - Archivio Istituzionale Open Access dell'Università di Torino

\title{
Association of the glycoxidative stress marker pentosidine with equine laminitis
}

\section{This is the author's manuscript}

Original Citation:

Availability:

This version is available http://hdl.handle.net/2318/131522

since 2017-07-27T14:19:34Z

Published version:

DOI:10.1016/j.tvjl.2012.10.030

Terms of use:

Open Access

Anyone can freely access the full text of works made available as "Open Access". Works made available under a Creative Commons license can be used according to the terms and conditions of said license. Use of all other works requires consent of the right holder (author or publisher) if not exempted from copyright protection by the applicable law. 


\section{(3) \\ UNIVERSITÀ DEGLI STUDI DI TORINO}

This Accepted Author Manuscript (AAM) is copyrighted and published by Elsevier. It is posted here by agreement between Elsevier and the University of Turin. Changes resulting from the publishing process - such as editing, corrections, structural formatting, and other quality control mechanisms - may not be reflected in this version of the text. The definitive version of the text was subsequently published in

The Veterinary Journal

Volume 196, Issue 3, June 2013, Pages 445-450

http://dx.doi.org/10.1016/j.tvj1.2012.10.030

You may download, copy and otherwise use the AAM for non-commercial purposes provided that your license is limited by the following restrictions:

(1) You may use this AAM for non-commercial purposes only under the terms of the CC-BY-NCND license.

(2) The integrity of the work and identification of the author, copyright owner, and publisher must be preserved in any copy.

(3) You must attribute this AAM in the following format: Creative Commons BY-NC-ND license (http://creativecommons.org/licenses/by-nc-nd/4.0/deed.en), [+ Digital Object Identifier link to the published journal article on Elsevier's ScienceDirect ${ }^{\circledR}$ platform $]$ 


\begin{abstract}
Ponies suffering from recurrent episodes of laminitis when grazed at pasture (pastureassociated laminitis) exhibit phenotypes similar to those associated with human metabolic syndrome. In humans, evidence suggests that the obesity-related morbidities associated with metabolic syndrome, including diabetes and cardiovascular disease, are caused by an increase in the production of advanced glycoxidation end-products (AGEs). These end-products have been recognised as putative pro-inflammatory mediators and are considered a 'risk factor' for human health. However, the evaluation of AGEs in laminitic ponies has not been explored.
\end{abstract}

The aim of this study was to compare plasma concentrations of the AGE pentosidine (PENT) in ponies presenting with clinical features of equine metabolic syndrome (EMS) with a history of recent laminitis and/or showing signs of laminitis at the time of sampling (LP) with those with no prior history of clinical laminitis (NL). Age, body condition score (BCS) and bodyweight were recorded and blood samples collected for the measurement of plasma concentrations of PENT, glucose, insulin, triglycerides (TG), non-esterified fatty acids (NEFA) and cortisol. Insulin sensitivity was assessed by the reciprocal of the square root of insulin (RISQI) and the insulin:glucose ratio. Plasma PENT concentrations were twofold higher $(\mathrm{P}<0.005)$ in LP than in NL ponies. Significant $(\mathrm{P}<0.05)$ correlations were also evident between PENT and insulin, RISQI, TG and age. These preliminary findings are consistent with the hypothesis that glycoxidation in laminitis is associated with EMS.

Keywords Ponies; Laminitis; Pentosidine; Advanced glycoxidation end-products;

Equine metabolic syndrome 
Introduction

It has recently been observed that ponies prone to recurrent episodes of laminitis when grazed at pasture (pasture-associated laminitis) exhibit a phenotype similar to human metabolic syndrome (HMS) (Treiber et al., 2006 and Geor, 2008). In HMS, the clustering of obesity (especially visceral adiposity), insulin resistance (IR), atherogenic dyslipidaemia and elevated blood pressure, and evidence of pro-inflammatory and pro-thrombotic states have been associated with a fivefold increase in the risk of type 2 diabetes mellitus (Alberti et al., 2005 and Potenza and Mechanick, 2009). Similarly, the clustering of obesity, regional accumulations of fat, IR, hyperleptinaemia and hyperinsulinaemia predicts an increase in the risk of pasture-associated laminitis in ponies presenting this metabolic syndrome phenotype (equine metabolic syndrome, EMS) (Geor, 2008).

It is widely hypothesised that IR and its associated hyperinsulinaemia are pivotal in the pathological manifestations of metabolic syndrome, particularly in the susceptibility to laminitis. Indeed, clinical and histopathological laminitis can be induced experimentally in horses and ponies by use of a euglycaemic hyperinsulinaemic clamp (Asplin et al., 2007 and de Laat et al., 2010), a model which allows the developmental and acute stages of hyperinsulinaemic laminitis to be studied. Furthermore, this insulin-induced model of laminitis was recently shown to be associated with the accumulation of advanced glycoxidation end-products (AGEs) in the lamellar tissue of horses (de Laat et al., 2012). 
In human medicine, AGEs have been recognised as putative pro-inflammatory mediators (Galli et al., 2005) and considered a 'risk factor' for human health. AGEs are produced by the Maillard reaction in food or endogenously (Grunwald et al., 2006). The formation of AGEs involves not only the metabolic reduction of carbohydrates (glucose, galactose, fructose, ribose), but also the intermediates of glucose metabolism (such as glucose-6-phosphate, fructose-6-phosphate, and glyceraldehyde), lipid peroxidation molecules, metabolites of the polyol pathway (fructose or fructose 3-phosphate) and carbonyl compounds; these reactions involve also the formation of reactive oxygen species (ROS). AGEs may in turn activate their receptors leading to inflammation through nuclear factor $\kappa \mathrm{B}$ signalling (Bierhaus et al., 2001), increasing oxygen free radical formation and the induction and release of pro-inflammatory cytokines, adhesion molecules and growth factors (Bierhaus et al., 1998). The accumulation of AGEs is associated with the pathogenesis of chronic conditions, like diabetes mellitus (Singh et al., 2001), due to the hyperglycaemic condition. However, AGEs can also be produced under euglycaemic conditions since they can be formed as a result of oxidant stress and along inflammatory pathways (Yan et al., 2003).

In contrast to humans, diabetes mellitus is rare in horses, although insulin resistance (IR) in horses and ponies is being increasingly recognised (Geor, 2008). Increases in the circulating concentrations of AGEs have been associated with IR in non-obese, non-diabetic human subjects (Tan et al., 2011). As AGE formation is inevitable under pathophysiological conditions (Sanguineti et al., 2008) and laminitis-prone ponies suffer from a naturally occurring disorder that resembles the HMS, the question arises whether glycoxidation plays an explicit role in laminitis. One of the well-characterised AGEs is pentosidine (PENT), which is considered to be a major glycoxidative end-product (Suliman et al., 2003) and is 
widely used as a measure of total AGE accumulation in plasma or other tissues (van Deemter et al., 2009).

The objective of the present study was therefore to test the hypothesis that the glycoxidation cascade plays a role in EMS-associated laminitis. Plasma concentrations of AGE pentosidine were determined in ponies with no prior history of clinical laminitis (NL) and compared with those in ponies exhibiting clinical features of EMS and with a recent history of laminitis and/or showing signs of laminitis at the time of sampling (LP). According to the above hypothesis, if the glycoxidation cascade plays a role in EMS-associated laminitis, increased PENT concentrations would be expected in the plasma of LP ponies. We also investigated the possible relationship between plasma PENT concentrations and other metabolic variables typically altered in EMS. To the authors' knowledge, the production of AGE pentosidine in ponies affected by EMS and laminitis has not been previously studied or reported.

Materials and methods

Animals and selection criteria

All procedures were approved by the Virginia Tech Institutional Animal Care and Use Committee. The samples included in the study were collected during the spring season (March to May) from 31 ponies (28 females, 1 stallion, 2 geldings), all of which belonged to a previously studied herd (Carter et al., 2009b and Treiber et al., 2006).

Thirty of the animals were Welsh or Dartmoor Pony pure breeds, and one animal was a crossbreed; all ponies descended from pony bloodlines residing on the selected farm. All ponies were maintained under similar pasture conditions composed of mixed grass (fescue, orchard grass and Kentucky bluegrass) and legume (clover) species; ponies were not provided with 
supplemental feeds (average nutrient composition of the pasture forage is reported in Table 1).

The criteria for inclusion in the study were based on the presence or absence of a history of clinical laminitis based on farm records. Ponies were excluded from the study if clinical examination exposed evidence of pituitary pars intermedia dysfunction (PPID). The screening for PPID included the measurement of plasma adrenocorticotrophic hormone (ACTH) concentrations; this measurement was performed in March (Animal Health Diagnostic Center, Cornell University, Ithaca, New York). All ponies included in the study had plasma ACTH levels within the laboratory reference range $(9-35 \mathrm{pg} / \mathrm{mL})$. Ponies that had never shown any clinical signs of laminitis up until the time of sampling were classified as never laminitic (NL) $(\mathrm{n}=10)$. The laminitic ponies (LP) group included animals that had experienced at least one episode of laminitis during the 12-month period prior to sampling $(\mathrm{n}=9)$ and/or were showing signs of laminitis just prior to sampling $(n=12)$, diagnosed by an experienced veterinarian. All LP $(n=21)$ exhibited other clinical features of EMS, including obesity and/or regional adiposity and previous evidence of hyperinsulinaemia.

Clinical data and blood sampling

Ponies were brought in from pasture the night (approximately 20:00 h) prior to their examination and sampling. Ponies were housed in a dry lot and provided group access to a small quantity ( $\sim 0.5 \mathrm{~kg}$ per head) of orchard-grass hay (dry matter basis: crude protein $11.5 \%$, acid detergent fibre $39 \%$, neutral detergent fibre $59 \%$, water-soluble carbohydrates $5.1 \%$ and starch $1.5 \%$ ). No other feed or forage was offered until after completion of sampling. At 07:00 h, ponies were temporarily housed in $3 \times 3 \mathrm{~m}$ stalls and blood samples were collected between 08:00 and 10:00 h. Blood samples were collected by jugular venepuncture into $10 \mathrm{~mL}$ Vacutainer tubes containing K-EDTA and sodium heparin as 
anticoagulant (Becton, Dickinson). Samples were placed immediately onto ice and centrifuged within 30 min of sampling at 3000 g. Plasma fractions were then drawn off and stored at $-80{ }^{\circ} \mathrm{C}$ until analysis.

All ponies were weighed on an electronic weighing scale and their body condition score (BCS) calculated according to a 1-9 scale, whereby 1 indicated emaciation and 9 indicated extremely fat (Henneke et al., 1983). In this population of ponies, a BCS between 4 and 6 was classified as a moderate body condition, while a BCS exceeding 6 was classified as obese (Carter et al., 2009a).

Samples analyses

Plasma samples were analysed for glucose, triglyceride, non-esterified fatty acid (NEFA) and insulin concentrations, as previously described (Treiber et al., 2006 and Carter et al., 2009b). In brief, plasma glucose (G), triglycerides (TG) and NEFA were analysed by use of an automated analyser (Beckman Instruments) and enzymatic assay kits (Triglyceride GPO reagent; Glucose Procedure No. 16-UV, Sigma Diagnostics; NEFA, Wako Autokit). Plasma insulin concentrations were determined by use of a radioimmunoassay (RIA) previously validated for equine insulin (Coat-A-Count Insulin, Diagnostic Products) (Freestone et al., 1991), and cortisol concentrations were determined using an RIA (Coat-A-Count Cortisol, Diagnostic Products) previously validated for equine cortisol (Alexander and Irvine, 1998). All assays were performed in duplicate.

Calculation of basal proxies

Basal values of plasma insulin and glucose were used to calculate the following two proxies of insulin sensitivity (as previously described in Treiber et al., 2005): (1) the reciprocal of the 
square root of insulin $(\mathrm{RISQI})=1 / \sqrt{ }$ basal insulin concentration; and $(2)$ the basal insulin to glucose ratio (I:G = insulin/glucose) (Treiber et al., 2005).

Pentosidine analyses

Plasma pentosidine concentrations were measured by high performance liquid chromatography (HPLC), following the method of Odetti et al. (1992) with slight modifications. Briefly, chromatography was performed using a Waters HPLC system equipped with a Waters 570 fluorimeter detector. Each sample was hydrolysed with $6 \mathrm{~mol} / \mathrm{L}$ hydrochloric acid (VWR International) for $18 \mathrm{~h}$ at $110{ }^{\circ} \mathrm{C}$ in borosilicate screw-capped tubes, dried in a Speed-Vac concentrator and then reconstituted in HPLC-grade water containing $0.01 \mathrm{~mol} / \mathrm{L}$ heptafluorobutyric acid (HFBA, Pierce Prodotti Gianni), filtered and injected into a Waters C18 XTerra Reverse-Phase column $(25 \mathrm{~cm} \times 0.46 \mathrm{~cm}, 5 \mu \mathrm{m})$ with a curvilinear gradient program. Pentosidine peaks were monitored using a fluorescent detector at $\lambda$ ex 335 $\mathrm{nm}$ and $\lambda \mathrm{em} 385 \mathrm{~nm}$ wavelengths. A pentosidine synthetic standard (prepared as described by Grandhee and Monnier, 1991) was injected at the start of each run to determine the pentosidine concentration in the sample by peak area comparison. The amount of pentosidine was expressed as pmol per mg of plasma protein content.

Protein content determination

Plasma protein content was determined using the BCA protein assay kit according to the manufacturer's instructions (Thermo Scientific).

Statistical analysis

All statistical analyses were performed using Graph Pad Prism 4.0 software (Graph Pad Software). The assumption of normality was tested using the Kolgoromov-Smirnov test. 
Statistical significance was considered at $\mathrm{P} \leqslant 0.05$. Normally distributed variables were expressed as means plus standard deviations, while non-normally distributed variables were expressed as medians plus interquartile ranges (IR). The Mann-Whitney U test was used to compare LP and NL group data for plasma concentrations of pentosidine, insulin, triglycerides, glucose, NEFA and cortisol, as well as values of RISQI, I:G, BCS, animal age and bodyweight (BW). Finally, the relationships between plasma concentrations of pentosidine and the other metabolic parameters were investigated using the one-tailed Spearman's correlation coefficient (rs).

Results

Clinical data

The mean age, BW and BCS for each experimental group are reported in Table 2. LP ponies were older $(\mathrm{P}<0.001)$ than NL ponies. No statistical differences were detected between groups for BCS or BW. Ninety per cent $(19 / 21)$ of the LP and $80 \%$ of the NL ponies $(8 / 10)$ were considered obese (BCS > 6). All other ponies fell into the moderate body condition category (BCS $>$ than 4 and $\leqslant 6)$.

Plasma biochemical analytes

The results for the biochemical analyses of plasma samples are reported in Table 2. No significant differences were detected between LP and NL ponies for either plasma glucose or NEFA. Plasma concentrations of triglycerides were significantly higher in LP than in NL ponies $(\mathrm{P}=0.03)$ as were those of insulin. Cortisol measurements were available for just 19 subjects $(\mathrm{NL} \mathrm{n}=9 ; \mathrm{LP} \mathrm{n}=11)$; no differences were detected $(\mathrm{P}=0.40)(10.07$ [9.25-11.72] vs. 11.79 [8.60-14.16] $\mu \mathrm{g} / \mathrm{dL}, \mathrm{NL}$ vs. LP, respectively). 
Pentosidine analysis

Mean values of plasma pentosidine were almost twofold higher in the LP $(9.75 \pm 0.98$ $\mathrm{pmol} / \mathrm{mg}$ protein) than in NL ponies $(5.26 \pm 0.79 \mathrm{pmol} / \mathrm{mg}$ protein, $\mathrm{P}<0.005)$ ( Table 2$)$. Insulin sensitivity

The proxy measurement of insulin sensitivity (RISQI) was significantly lower in the LP group $(\mathrm{P}<0.001)$. Moreover, the $\mathrm{I}: \mathrm{G}$ ratio was significantly higher in $\mathrm{LP}$ than in NL ponies, suggesting the existence of insulin resistance in the laminitic ponies ( Table 2).

Components of EMS associated with plasma PENT

Combining the data from the two groups, positive correlations transpired for plasma concentrations of PENT vs. insulin ( $\mathrm{rs}=+0.69, \mathrm{P}<0.001$ ), PENT vs. I:G ( $\mathrm{rs}=+0.64, \mathrm{P}<$ 0.01), and PENT vs. TG ( $\mathrm{rs}=+0.33, \mathrm{P}<0.03$ ); a negative correlation was observed between PENT and RISQI score ( $\mathrm{rs}=-0.56, \mathrm{P}<0.0005$ ) ( Fig. 1). No significant correlation existed between PENT and age ( $\mathrm{rs}=+0.26, \mathrm{P}=0.08)$ or between PENT and cortisol $(\mathrm{rs}=+0.28, \mathrm{P}=$ $0.24)$.

\section{Discussion}

The present study is the first to associate a marker of glycoxidation (plasma PENT concentration) with EMS-associated laminitis and to identify relationships between plasma PENT concentrations and various metabolic variables typically altered in EMS. Consistent with previous findings from this group of ponies (Treiber et al., 2006 and Carter et al., 2009b), the LP ponies exhibited hyperinsulinaemia, in comparison with NL ponies ( $<$ < 
0.001), and insulin resistance, as suggested by a significantly lower RISQI $(\mathrm{P}<0.001)$ and higher I:G ratio $(\mathrm{P}<0.001)$, as well as hypertriglyceridaemia $(\mathrm{P}<0.03)$.

In the current study, the basal proxy RISQI was used as this measure has been shown to be negatively correlated to insulin sensitivity determined by the more rigorous minimal model method (Treiber et al., 2005). While being less invasive and more feasible, the accuracy of proxy measures has been questioned. Proxy measurements of insulin sensitivity used in man are based on fasting glucose and insulin concentrations, which ensures a steady state of insulinaemia (Muniyappa et al., 2008). One limitation of the current study was that the ponies were provided access to a small amount of hay during the overnight period prior to blood sampling. This small quantity of hay was provided to counter stress associated with removal from pasture and also in recognition of the fact that horses evolved to graze with short fasting state no longer than 3-5 h at a time (Ralston, 1984). Arguably, between-pony differences in hay consumption during the night-time hours may have accounted for some of the group variation in outcome measures. However, any effect on measured variables (e.g. glucose and insulin concentrations) was likely minimal given the small amount of hay provided and its very low NSC content.

Recent studies have identified metabolic risk factors for laminitis, but as yet it has not been determined which of these factors is critical for the onset of clinical laminitis even if hyperinsulinaemia could play an important role (Asplin et al., 2007 and de Laat et al., 2010). According to de Laat et al. (2012), a significant accumulation of AGEs is evident in the lamellae of horses following 48 h hyperinsulinaemic clamp technique, which induces Obel grade 2 laminitis in Standardbred horses. The same authors reported a failure to detect an increase in oxidative protein damage (protein carbonyl) and cellular lipid peroxidation 
(MDA) during the induction of laminitis. Limited evidence of oxidative stress was also reported for more chronic forms of endocrinopathic laminitis (Keen et al., 2004 and Treiber et al., 2009).

The higher plasma concentrations of pentosidine in LP compared to NL ponies suggested that glycoxidation may play a role in the pathogenesis of EMS and its related laminitis. Plasma pentosidine is a reliable marker of the glycoxidation cascade (Nitti et al., 2005). The accumulation of AGEs in tissues significantly increases the level of inflammation in the body (Bengmark, 2007). AGEs induce chemical modifications and the cross-linking of tissue proteins, mediating various tissue dysfunctions and causing the release of pro-inflammatory molecules and cytokines through their interaction with specific AGE receptors (Sanguineti et al., 2008).

Previous studies have stated that ageing could play a role in the development of laminitis (Alford et al., 2001). Indeed, the animals of the LP group of the present study were older than the ponies of the NL group $(\mathrm{P}<0.001)$. As laminitis may be an age-related disease, especially in animals with PPID, it is possible that glycoxidative damage could contribute to an increased total AGE burden in the face of an inability to excrete these compounds ( Uribarri et al., 2007). Additionally, none of the ponies had clinical evidence of PPID, and plasma ACTH concentrations were within the laboratory reference range.

Pentosidine was first studied in collagen as a marker of glycoxidation rate. Levels of pentosidine can increase with age in different mammalian species, presenting an inverse correlation between species longevity and glycoxidation rates (Sell et al., 1996). In horses, previous studies have reported the accumulation of pentosidine with age in joint cartilage 
specimens (Brama et al., 2000), as well as in tendons within the sesamoid region (Lin et al., 2005). In the present study, no significant correlation between pentosidine and animal age was detected, even if LP ponies were twice the age of the NL cases. This result might be due to the fact that plasma is not the best 'tissue' for studying the link between AGEs accumulation and ageing. Tissue components that exhibit a slow turnover, such as skin collagen (Sell et al., 1996), are more suitable to evaluate the effect of ageing. Nonetheless, it is unlikely that the higher PENT concentrations in the LP group is simply due to an effect of ageing as studies in healthy humans have demonstrated a only small differences in plasma pentosidine between subjects in their 20s vs. those in their 90s (Odetti et al., 2005).

Alternatively, a more significant increase of PENT was observed with a metabolic disturbances, such as diabetes. It is interesting to note that the plasma concentrations of PENT in human diabetic patients are much lower $(2.09 \pm 0.16 \mathrm{pmol} / \mathrm{mg})$ (Sugiyama et al., 1998) than the concentrations measured in the LP and NL ponies. In human diabetes, hyperglycaemia and the auto-oxidation of glucose provides substrate for the glycoxidative stress pathway. However, persistent hyperglycaemia and diabetes mellitus are apparently rare in horses (Johnson et al., 2005 and Durham et al., 2009), suggesting that factors other than glucose (e.g. insulin) could potentially lead to the increase in AGEs.

Each tissue responds to high concentrations of AGEs in different ways (Nitti et al., 2005). In horses, the level of superoxide dismutase (SOD) (an antioxidant enzyme) in the lamellae is reportedly low (Loftus et al., 2007), which could make the laminar tissues more susceptible to glycoxidative damage. The interactions between AGEs with their specific receptor (RAGE) may be linked to the increased generation of ROS by multiple mechanisms such as by decreasing the activity of SOD and catalase, diminishing glutathione stores, or the activation 
of protein kinase C (Ramasamy et al., 2005). Glycoxidation may contribute to endothelial dysfunction (Chappey et al., 1997), the cross-linking of collagen and interstitial matrix with reduced turnover and functionality (Avery and Bailey, 2006), the increased release of cytokines that contributes to inflammation and tissue damage (Bengmark, 2007) and to the worsening of insulin resistance (Sandu et al., 2005).

The identification of higher plasma PENT levels in the laminitic group of ponies is a promising result for the study of the inflammatory nature of equine metabolic syndrome and laminitis since AGEs are well-known pro-oxidant and pro-inflammatory molecules. As the incidence of pasture-associated laminitis tends to be highest during the spring and early summer, in association with the peak accumulation of non-structural carbohydrates in pasture forage (Hoffman et al., 2001, Kronfeld et al., 2006, Bailey et al., 2008 and Geor, 2009), it would be interesting to evaluate the consumption of dietary AGEs and their precursors that act as glycotoxins and that may also contribute to a state of elevated oxidative and inflammatory stress.

\section{Conclusions}

This study reports for the first time that plasma pentosidine concentrations are higher in ponies exhibiting clinical features of EMS and a recent history of/concurrent laminitis compared with ponies with no recent history of laminitis. These preliminary findings were obtained from a small sample of ponies in a single herd, thus further research considering other populations is needed to confirm the involvement of the glycoxidation pathway in the pathogenesis of endocrinopathic laminitis. 
Conflict of interest statement

None of the authors have any financial or personal relationships that could inappropriately influence or bias the content of this paper.

Acknowledgements

This study was supported by grants from the University of Turin (ex 60\% Grant 2007). The paper is dedicated to Daniela Storace who died suddenly in August 2010. Her death is a huge loss for the research community of the DIMI.

\section{References}

1. Alberti, K.G., Zimmet, P., Shaw, J., 2005. The metabolic syndrome-a new worldwide definition. Lancet 366, 1059-1062.

2. Alexander, S. L., C. H. G. Irvine., 1998. The effect of social stress on adrenal axis activity in horses: The importance of monitoring corticosteroid-binding globulin capacity. Journal of Endocrinology 157, 425-432.

3. Alford, P., Geller, S., Richardson, B., Slater, M., Honnas, C., Foreman, J., Robinson, J., Messer, M., Roberts, M., Goble, D., Hood, D., Chaffin, M., 2001. A multicenter, matched case-control study of risk factors for equine laminitis. Preventive Veterinary Medicine 49, 209-222.

4. Asplin, K. E., Sillence M.N., Pollitt C.C., McGowana C. M.,2007. Induction of laminitis by prolonged hyperinsulinaemia in clinically normal ponies. Veterinary Journal $174,530-5$.

5. Avery, N.C., Bailey, A.J., 2006. The effects of the Maillard reaction on the physical properties and cell interactions of collagen. Pathologie Biologie (Paris) 54, 387-395.

6. Bailey, S.R., Habershon-Butcher, J.L., Ransom, K.J., Elliott, J., Menzies-Gow, N.J., 2008. Hypertension and insulin resistance in a mixed-breed population of ponies predisposed to laminitis. American Journal of Veterinary Research 69, 122-129.

7. Bengmark, S., 2007. Advanced glycation and lipoxidation end products--amplifiers of inflammation: the role of food. Journal of Parenteral and Enteral Nutrition 31, 430-440.

8. Bierhaus, A., Schiekofer, S., Schwaninger, M., Andrassy, M., Humpert, P.M., Chen, J., Hong, M., Luther, T., Henle, T., Kloting, I., Morcos, M., Hofmann, M., Tritschler, H., 
Weigle, B., Kasper, M., Smith, M., Perry, G., Schmidt, A.M., Stern, D.M., Haring, H.U., Schleicher, E., Nawroth, P.P., 2001. Diabetes-associated sustained activation of the transcription factor nuclear factor-kappaB. Diabetes 50, 2792-2808.

9. Bierhaus A., Hofmann M.A., Ziegler R., Nawroth P.P., 1998. AGEs and their interaction with AGE-receptors in vascular disease and diabetes mellitus. I. The AGE concept. Cardiovascular Research 37, 586-600.

10. Borer K.E., Bailey S.R., Menzies Gow N.J. Harris P.A. . Elliot J., 2011. Use of proxy measurements of insulin sensitivity and insulin secretory response to distinguish between normal and previously laminitic ponies. Equine Veterinary Journal. doi: 10.1111/j.20423306.2011.00475.x.

11. Brama, P.A., Tekoppele, J.M., Bank, R.A., Barneveld, A., Firth, E.C., van Weeren, P.R., 2000. The influence of strenuous exercise on collagen characteristics of articular cartilage in Thoroughbreds age 2 years. Equine Veterinary Journal 32, 551-554.

12. Carter, R.A., Geor, R.J., Burton Staniar, W., Cubitt, T.A., Harris, P.A., 2009a. Apparent adiposity assessed by standardised scoring systems and morphometric measurements in horses and ponies. The Veterinary Journal 179, 204-210.

13. Carter, R.A., Treiber, K.H., Geor, R.J., Douglass, L., Harris, P.A., 2009b. Prediction of incipient pasture-associated laminitis from hyperinsulinaemia, hyperleptinaemia and generalised and localised obesity in a cohort of ponies. Equine Veterinary Journal 41, 171178.

14. Chappey, O., Dosquet, C., Wautier, M.P., Wautier, J.L., 1997. Advanced glycation end products, oxidant stress and vascular lesions. European Journal of Clinical Investigation 27, 97-108.

15. Choi Y.G., Lim S., 2010. N(ع)-(carboxymethyl)lysine linkage to $\alpha$-synuclein and involvement of advanced glycation end products in $\alpha$-synuclein deposits in an MPTPintoxicated mouse model. Biochimie 92, 1379-1386.

16. de Laat M.A., Kyaw-Tannera M.T, Sillence M.N., McGowanc C.M, Pollitt, C.C, 2012 Advanced glycation endproducts in horses with insulin-induced laminitis. Veterinary Immunology and Immunopathology. doi: 10.1016/j.vetimm.2011.12.016.

17. de Laat M.A., McGowan C.M., Sillence M.N., Pollit C.C., 2010. Equine laminitis: induced by $48 \mathrm{~h}$ hyperinsulinaemia in standardbred horses. Equine Veterinary Journal 42, $129-135$.

18. Durham, A.E., Hughes, K.J., Cottle, H.J., Rendle, D.I., Boston, RC., 2009. Type 2 diabetes mellitus with pancreatic beta cell dysfunction in 3 horses confirmed with minimal model analysis. Equine Veterinary Journal 41, 924-929.

19. Freestone, J.F., Wolfsheimer, K.J., Kamerling, S.G., Church, G., Hamra, J., Bagwell, C., 1991. Exercise induced hormonal and metabolic changes in Thoroughbred horses: effects of conditioning and acepromazine. Equine Veterinary Journal 23, 219-223. 
20. Galli F., Benedetti S., Floridi A., Canestrari F., Piroddi M., Buoncristiani E., Buoncristiani U., 2005. Glycoxidation and inflammatory markers in patients on treatment with PMMA-based protein-leaking dialyzers. Kidney International 67, 750-759.

21. Geor R., 2008. Metabolic predispositions to laminitis in horses and ponies: obesity, insulin resistance and metabolic syndromes. Journal of Equine Veterinary Science 28, 753759.

22. Geor, R.J., 2009. Pasture-associated laminitis. Veterinary Clinics of North America: Equine Practice 25, 39-50.

23. Golovchenko I., Goalstone M.L., Watson P., Brownlee M., Draznin B., 2000. Hyperinsulinemia enhances transcriptional activity of nuclear factor-kappaB induced by angiotensin II, hyperglycemia, and advanced glycosylation end products in vascular smooth muscle cells. Circulation Research, 27,746-752.

24. Grandhee, S.K., Monnier, V.M., 1991. Mechanism of formation of the Maillard protein cross-link pentosidine. Glucose, fructose, and ascorbate as pentosidine precursors. The Journal of Biological Chemistry 266, 11649-11653.

25. Grunwald, S., Krause, R., Bruch, M., Henle, T., Brandsch, M., 2006. Transepithelial flux of early and advanced glycation compounds across Caco-2 cell monolayers and their interaction with intestinal amino acid and peptide transport systems. British Journal of Nutrition 95, 1221-1228.

26. Henneke, D.R., Potter, G.D., Kreider, J.L., Yeates, B.F. 1983. Relationship between condition score, physical measurements and body fat percentage in mares. Equine Veterinary Journal 15, 371-372.

27. Hoffman R.M., Kronfeld D.S., Cooper W.L., Harris P.A., 2003.Glucose clearance in grazing mares is affected by diet, pregnancy, and lactation. Journal Animal Science, 17641771 .

28. Hoffman, R.M., Wilson, J.A., Kronfeld, D.S., Cooper, W.L., Lawrence, L.A., Sklan, D., Harris, P.A., 2001. Hydrolyzable carbohydrates in pasture, hay, and horse feeds: direct assay and seasonal variation. Journal of Animal Science 79, 500-506.

29. Johnson, P.J., Scotty, N.C., Wiedmeyer, C., Messer, N.T., Kreeger, J.M., 2005. Diabetes mellitus in a domesticated Spanish mustang. Journal of the American Veterinary medical Association 226, 584-588.

30. Keen, J.A., McLaren, M., Chandler, K.J., McGorum, B.C., 2004. Biochemical indices of vascular function, glucose metabolism and oxidative stress in horses with equine Cushing's disease. Equine Veterinary Journal 36, 226-229.

31. Kronfeld, D.S., Treiber, K.H., Hess, T.M., Splan, R.K., Byrd, B.M., Staniar, W.B., White, N.W., 2006. Metabolic syndrome in healthy ponies facilitates nutritional countermeasures against pasture laminitis. Journal of Nutrition 136 (Suppl. ), 2090-2093. 
32. Lin, Y.L., Brama, P.A., Kiers, G.H., van Weeren, P.R., DeGroot, J., 2005. Extracellular matrix composition of the equine superficial digital flexor tendon: relationship with age and anatomical site. Journal of Veterinary Medicine. Series A: Physiology, Pathology, Clinical Medicine 52, 333-338.

33. Loftus, J.P., Belknap, J.K., Stankiewicz, K.M., Black, S.J., 2007. Laminar xanthine oxidase, superoxide dismutase and catalase activities in the prodromal stage of black-walnut induced equine laminitis. Equine Veterinary Journal 39, 48-53.

34. McFarlane D., 2007. Advantages and limitations of the equine disease, pituitary pars intermedia dysfunction as a model of spontaneous dopaminergic neurodegenerative disease. Ageing Research Reviews, 6, 54-63.

35. Muniyappa, R., Lee S., Chen H., Quon M. J., 2008. Current approaches for assessing insulin sensitivity and resistance in vivo: advantages, limitations, and appropriate usage. American Journal of Physiological - Endocrinology and Metabolism, 294, E15-E26.

36. Nitti, M., d'Abramo, C., Traverso, N., Verzola, D., Garibotto, G., Poggi, A., Odetti, P., Cottalasso, D., Marinari, U.M., Pronzato, M.A., Domenicotti, C., 2005. Central role of PKCdelta in glycoxidation-dependent apoptosis of human neurons. Free Radical Biology \& Medicine 38, 846-856.

37. Odetti, P., Fogarty, J., Sell, D.R., Monnier, V.M., 1992. Chromatographic quantitation of plasma and erythrocyte pentosidine in diabetic and uremic subjects. Diabetes 41, 153-159.

38. Odetti P., Rossi S., Monacelli F., Poggi A., Cirnigliaro M., Federici M., Federici A., 2005. Advanced glycation end products and bone loss during aging. Annals of the New York Academy of Sciences 1043, 710-717.

39. Potenza, M.V., Mechanick, J.I., 2009. The metabolic syndrome: definition, global impact, and pathophysiology. Nutrition in Clinical Practice 24, 560-577.

40. Ralston, S., L., 1984. Controls of Feeding in Horses. Journal of Animal Science 59, 1354-1361.

41. Ramasamy, R., Vannucci, S.J., Yan, S.S., Herold, K., Yan, S.F., Schmidt, A.M., 2005. Advanced glycation end products and RAGE: a common thread in aging, diabetes, neurodegeneration, and inflammation. Glycobiology 15, 16R-28R.

42. Sandu, O., Song, K., Cai, W., Zheng, F., Uribarri, J., Vlassara, H., 2005. Insulin resistance and type 2 diabetes in high-fat-fed mice are linked to high glycotoxin intake. Diabetes 54, 2314-2319.

43. Sanguineti, R., Storace, D., Monacelli, F., Federici, A., Odetti, P., 2008. Pentosidine effects on human osteoblasts in vitro. Annals of the New York Academy of Sciences 1126, 166-172.

44. Sell, D.R., Lane, M.A., Johnson, W.A., Masoro, E.J., Mock, O.B., Reiser, K.M., Fogarty, J.F., Cutler, R.G., Ingram, D.K., Roth, G.S., Monnier, V.M., 1996. Longevity and 
the genetic determination of collagen glycoxidation kinetics in mammalian senescence 93 , 485-490.

45. Singh, R., Barden, A., Mori, T., Beilin, L., 2001. Advanced glycation end-products: a review. Diabetologia 44, 129-146.

46. Sugiyama S., Miyata T., Ueda Y., Tanaka H., Maeda K., Kawashima S., Van Ypersele de Strihou C., Kurokawa K .J.,1998. Plasma levels of pentosidine in diabetic patients: an advanced glycation end product. Journal of the American Society of Nephrology 9, 16811688 .

47. Suliman, M.E., Heimburger, O., Barany, P., Anderstam, B., Pecoits-Filho, R., Rodriguez Ayala, E., Qureshi, A.R., Fehrman-Ekholm, I., Lindholm, B., Stenvinkel, P., 2003. Plasma pentosidine is associated with inflammation and malnutrition in end-stage renal disease patients starting on dialysis therapy. Journal of the American Society of Nephrology $14,1614-1622$.

48. Tan, K.C., Shiu S.W., Wong Y.,Tam X., 2011. Serum advanced glycation end products (AGEs) are associated with insulin resistance. Diabetes/Metabolism Research and Reviews, 27, 488-492.

49. Treiber, K., Carter, R., Gay, L., Williams, C., Geor, R., 2009. Inflammatory and redox status of ponies with a history of pasture-associated laminitis. Veterinary Immunology and Immunopathology 129, 216-220.

50. Treiber, K.H., Kronfeld, D.S., Hess, T.M., Boston, R.C., Harris, P.A., 2005. Use of proxies and reference quintiles obtained from minimal model analysis for determination of insulin sensitivity and pancreatic beta-cell responsiveness in horses. American Journal of Veterinary Research 66, 2114-2121.

51. Treiber, K.H., Kronfeld, D.S., Hess, T.M., Byrd, B.M., Splan, R.K., Staniar, W.B., 2006. Evaluation of genetic and metabolic predispositions and nutritional risk factors for pasture-associated laminitis in ponies. Journal of the American Veterinary Medical Association 228, 1538-1545.

52. Unoki, H., Bujo, H., Yamagishi, S., Takeuchi, M., Imaizumi, T., Saito, Y., 2007. Advance glycation end products attenuate cellular insulin sensitivity by increasing the generation of intracellular reactive oxygen species in adipocytes. Diabetes Research and Clinical Practice 76, 236-244.

53. Uribarri, J., Cai, W., Peppa, M., Goodman, S., Ferrucci, L., Striker, G., Vlassara, H., 2007. Circulating glycotoxins and dietary advanced glycation endproducts: two links to inflammatory response, oxidative stress, and aging. Journals of Gerontology Series A: Biological Sciences and Medical Sciences 62, 427-433.

54. van Deemter, M., Ponsioen, T.L., Bank, R.A., Snabel, J.M., van der Worp, R.J., Hooymans, J.M., Los, L.I., 2009. Pentosidine accumulates in the aging vitreous body: a gender effect. Experimental Eye Research 88, 1043-1050. 
55. Yan S.F., Ramasamy R., Naka Y., Schmidt A.M.,2003. Glycation, inflammation, and RAGE: a scaffold for the macrovascular complications of diabetes and beyond. Circulation Research 93, 1159-1169. 


\section{Table 1}

Average nutrient composition ${ }^{\mathrm{a}}$ reported as $\%$ on dry matter basis for cool season grass pasture in northern Virginia over grazing seasons. Data courtesy of Dr. Kibby Treiber.

\begin{tabular}{llllllll}
\hline Month & CP \% & Starch \% & WSC \% & Fructan \% & NDF\% & ADF \% & ESC \% \\
\hline January & 11.23 & 0.35 & 1.78 & 0 & 48.63 & 25.00 & 2.45 \\
March & 9.65 & 0.45 & 0.85 & 0 & 47.35 & 24.40 & 1.20 \\
May & 19.47 & 1.03 & 12.37 & 3.80 & 38.47 & 16.70 & 8.57 \\
July & 18.05 & 0.93 & 6.73 & 0.05 & 49.88 & 22.60 & 6.68 \\
September & 20.03 & 0.95 & 5.9 & 2.15 & 53.43 & 31.20 & 3.75 \\
\hline
\end{tabular}

$\mathrm{CP}$, crude protein; WSC, water soluble carbohydrates; NDF, neutral detergent fibre; ADF, acid detergent fibre; ESC, ethanol soluble carbohydrates.

${ }^{a}$ Data summarised for each month over three consecutive days of sampling during the first 2 weeks of each month.

Analyses were performed at Dairy One DHIA Forage Testing Laboratory, Ithaca, NY 
Table 2

Age, body weight, BCS, glucose, insulin, triglycerides, NEFA, pentosidine and basal proxies in never laminitic (NL) and laminitic ponies (LP).

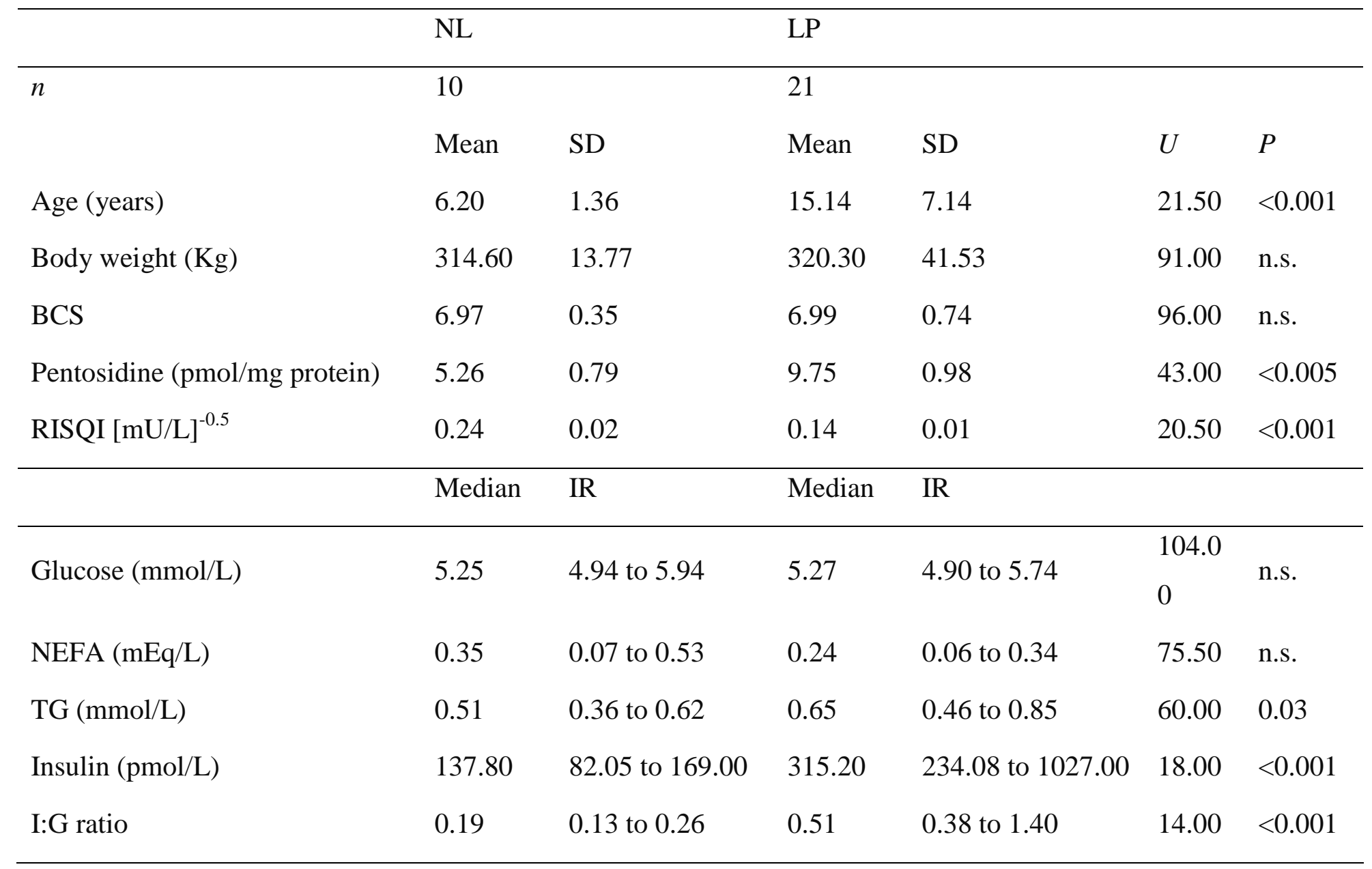

BCS, body condition score; RISQI, reciprocal of the square root of insulin; NEFA, nonesterified fatty acids; I:G, insulin to glucose ratio; TG, triglyceride; n.s., not significant, $P>0.05 ; \mathrm{SD}$, standard deviation; IR, interquartile range $\left(25^{\text {th }}\right.$ and $75^{\text {th }}$ percentiles $)$. 


\section{Figure legends}

Fig. 1. Correlation between plasma pentosidine (PENT) and RISQI score in never laminitic $(\mathrm{NL}, \mathrm{O}$ circles) and laminitic ponies $(\mathrm{LP}, \bullet$ dot points). The Spearman's correlation coefficient was calculated using Graph Pad software; a significant negative correlation was observed $\left(P=0.0005, r_{s}=-0.56\right)$.

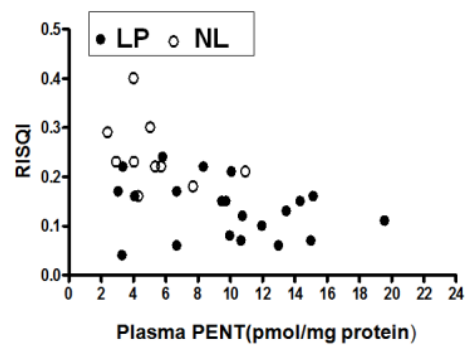

